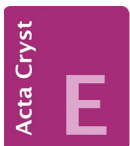

ISSN 2056-9890

\title{
anti-1-(Benzylamino)glyoxime. Corrigendum
}

\author{
Yavuz Köysal, ${ }^{a *}$ Șamil Ișık, ${ }^{a}$ Nursabah Sarıkavaklı! ${ }^{\mathbf{b}}$ and Fatih Eyduran ${ }^{\mathbf{b}}$
}

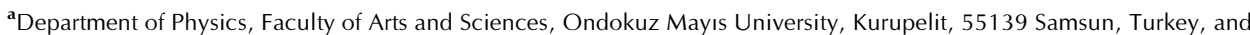

${ }^{\mathbf{b}}$ Department of Chemistry, Faculty of Arts and Sciences, Adnan Menderes University, Aydın, Turkey. *Correspondence

e-mail: yavuzk@omu.edu.tr

In the paper by Köysal et al. [Acta Cryst. (2004), E60, o515-o516], there was an error in the name of the last author.

The name of the last author in the paper by Köysal et al. (2004) is incorrect and should be 'Fatih Eyduran', as given above.

\section{References}

Köysal, Y., Işık, Ş., Sarıkavaklı, N. \& Erduran, F. (2004). Acta Cryst. E60, o515-o516. 